\title{
EFFECT OF NANO-THYMOQUINONE ON TUMOR NECROSIS FACTOR-A IN DMBA-INDUCED HAMSTER BUCCAL POUCH CARCINOGENESIS
}

\author{
Merhan N. El-Mansy*, Mona S. Shata* and Ola M. El-Borady**
}

\begin{abstract}
This study aimed to evaluate the anti-inflammatory effect of TQ-PLGA/PVA in treatment of oral carcinogenesis. Nanoparticles were fabricated via emulsification-solvent technique. Their characterization including the morphological analysis and size distribution on NPs performed using TEM and the structure composition was carried out via the FTIR. The charge determined via the DLS and ZP analysis. This study was carried out on 24 hamsters and divided into: group A served as negative control, group B was painted with DMBA for 6 weeks then subdivided into three subgroups: $\mathrm{B}_{1}$ served as positive control, $\mathrm{B}_{2}$ was injected with $\mathrm{TQ}, \mathrm{B}_{3}$ was injected with TQ-PLGA. Assessment of the blood cells counts, histologically, immunohistochemically through detection of TNF- $\alpha$ protein were performed. Comparisons between groups were performed using ANOVA. The results showed proper encapsulation for TQ-PLGA, significant regression in tumors histologically, marked improvement in blood cells and expression levels of TNF- $\alpha$ protein. Conclusion: systemic application of TQ-PLGA was considered a promising chemo-therapeutic agent in tumors regression.
\end{abstract}

KEY WORDS: Nano, Thymoquinone; PLGA; tumor regression; TNF- $\alpha$ protein.

\section{INTRODUCTION}

In 2017, oral cancer appeared in 369,200 new cases worldwide and approximately 145,328 deaths per year. Surgical treatment is considered the most debilitating and disfiguring line of treatment. To preserve organ's function, the role of chemotherapy (CT) was investigated. The main drawback is that it acts on normal cells that are actively reproducing.

Phytochemicals, natural plant-based compounds, have provided great promises as novel drug compounds. Thymoquinone (TQ) is the most abundant component of black seed oil. TQ has been reported to exhibit antioxidant, anti-inflammatory, chemopreventive and antiproliferative effect with minimally toxicity to normal cells." Despite these promising outcomes, the applicability of phytochemicals to human has met with only partial success due to poor bioavailability.

\footnotetext{
* Oral Pathology Department, Faculty of Dentistry, Suez Canal University

** Institute of Nanoscience and Nanotechnology, Kafrelsheikh University, Egypt
} 
Nano-carriers were found to modify drugs by increasing their bioavailability, efficacy, stability, solubility, sustaining their release and decreasing their toxicity-associated with high doses. Synthetic polymers such as PLGA and PVA can deliver drugs for days or weeks rather than natural polymer as chitosan. After degradation, they produce biocompatible byproducts. PLGA-encapsulated with TQ revealed sustained release characteristics, improved antioxidant potential, selective cytotoxic effect to cancer cells and facilitate its transportation to attain its target.

The carcinogen DMBA is a polycyclic aromatic hydrocarbon. It can mediate the neoplastic transformation by inducing DNA damage through adduction to adenine and guanine residues in DNA and generating excess reactive oxygen species. The Syrian golden hamster is an excellent model for oral carcinogenesis that closely correlates with common events involved in the development of human oral cancers.

Chronic inflammation is influenced by a wide array of factors not only contribute to inflammation and repair, but also to cancer progression. Tumor necrosis factor $(\mathrm{TNF}-\alpha)$ is involved in many biological functions. It is considered the master mediator of the pathogenesis of chronic inflammation. Therefore, anti-TNF therapies have become mainstay treatments for inflammatory diseases. It can enhance tumor growth directly via an inflammatory process through NF- $x \mathrm{~B}$ activation. In addition to, it can promote tumor expansion by increasing the production of matrix metallo-proteinases (MMPs) in tumor cells or its microenvironment. This study aimed to prepare, characterize and assess the anti-inflammatory effect of TQ-PLGA/PVA in DMBA-induced hamster buccal pouch carcinogenesis in comparison with free TQ.

\section{MATERIALS AND METHODS}

\section{Materials}

Polylactic acid/polyglycolic acid PLGA (75:25) from Evonik Company, U.S.A. Poly (vinyl alcohol) (PVA, MW: 30,000-70,000) and Thymoquinone powder were purchased from Sigma-Aldrich. The absolute ethanol (99.5-99.8\%) was obtained from Merck. Double distilled water was utilized for preparing all aqueous solutions.

The carcinogen chemicals: 7, 12 Dimethylbenz[a]-anthracene (DMBA) and heavy mineral oil to get DMBA $0.5 \%$ solution were purchased from Sigma Chemical Company, USA.

\section{The fabrication of TQ-PLGA-PVA NPs}

TQ-PLGA-PVA NPs were synthesized via an emulsification-solvent technique using $\mathrm{S} / \mathrm{O} / \mathrm{W}$ with slight modifications. Initially, the oil phase was prepared by dissolving $45 \mathrm{mg}$ of PLGA in 4 $\mathrm{ml}$ of ethanol and stirred for one hour at room temperature. After that $5 \mathrm{mg}$ of natural bioactive powder-TQ was added and stirred for 10 minutes to generate the S/O primary emulsion solution. In parallel, the aqueous phase was prepared in another clean beaker, while $1 \% \mathrm{w} / \mathrm{v}$ of PVA as surfactant dissolved in $20 \mathrm{ml}$ deionized water. Finally, S/O was added to $\mathrm{W}$ phase to emulsify under the probe ultrasonicator $(20,000 \mathrm{~Hz})$, for $20 \mathrm{~min}$ to produce $\mathrm{S} / \mathrm{O} / \mathrm{W}$ emulsion. Then the remaining organic solvent was evaporated by subjecting the resulting solution to stir for 2 hours. The formed NPs were then collected by centrifugation for mixture solution on 10,000 R.P.M for $30 \mathrm{~min}$ at $10^{\circ} \mathrm{C}$. The formed NPs were stored in the refrigerator until further characterization and applications.

\section{Characterization techniques for TQ-PLGA-PVA NPs}

High-resolution transmission electron microscopy (HR-TEM): The morphological properties of synthesized NPs such as shape and size was observed by the high resolution transmission 
electron microscopy (HR-TEM), model JOEL JEM-2010, that operate with an accelerating voltage $200 \mathrm{kV}$ and connected to Gatan digital camera model Erlangshen ES500, the images were taken by introducing one drop of the aqueous solution onto a copper grid of 400 mesh with carbon film.

Energy Dispersive X-ray microanalysis (EDX): The qualitative analysis regarding the existence of chemical elements in prepared solid material was provided using the EDX studies.

Fourier-transform infrared (FT-IR) spectral analysis: demonstration the structural composition of NPs were recognized via the Fourier-transform infrared (FT-IR) spectral analysis, using JASCO spectrometer in a scan range region from 4000 to $400 \mathrm{~cm}^{-1}$ while a $\mathrm{KBr}$ disc was used as a reference. The drug Encapsulation efficiency was detected by measuring the absorption spectrum of suspended NPs solution via spectrophotometer model shimaduz RF5301PC, double beam.

Dynamic Light Scattering (DLS) was performed for the prepared Nano sized vehicles in order to spot light on the average size distribution of the sample while it was reported as a poly-dispersity index (PDI) that obtained from measuring the distribution broadness of the particle size curve.

Zeta Potential (ZP): was evaluated via (Malvern, nano-series, Zetasizer, UK), connected to a helium-neon laser which operating at $90^{\circ}$ scattering angle and wavelength $633 \mathrm{~nm}$ at $25^{\circ} \mathrm{C}$. For each sample a triplicate trial were analyzed then the mean value was carefully reported. The elemental analysis of NPs powder sample was measured through Energy-dispersive X-ray spectroscopy (EDX) via JEOL model JSM-IT100 scanning electron microscope (SEM).

\section{Experimental design}

Sample size calculation was performed using G*Power version 3.1 9.2, University Kiel, Germany. Copyright (c) 1992-2014. The effect size was 0.99 using alpha $(\alpha)$ level of 0.05 and Beta $(\beta)$ level of 0.05 , i.e., power $=95 \%$; the estimated sample size (n) was a total of 20 samples. Total sample size was 24 samples. Each group had six samples.

Animals: This study was carried out after the approval of the ethical committee, faculty of dentistry, Suez Canal University (Ethical approval number 2019/238). It was carried out on twentyfour male Syrian golden hamsters (Mesocricetus auratus), weighing 90-100 grams. The animals were purchased from, Tiedor Blhars Research Institute, Cairo, Egypt. Animals were housed (six per cage) with controlled temperature, all animals were given water and recommended nutrient, ad libitum, and were divided as follow:

Group A ( $\mathrm{n}=6)$ : served as negative control and did not receive any type of treatment.

Group B ( $n=18)$ : The animals were painted with DMBA, three times/week on the left pouches by using hairbrush no. 4 for 6 weeks then the animals were subdivided into:

- Subgroup $B_{1}(n=6)$ were left without DMBA application and sacrificed at the end of the $12^{\text {th }}$ week of the study.

- Subgroup $B_{2} \quad(n=6)$ were injected intraperitoneal by TQ $0.001 \mathrm{mg} / \mathrm{kg}$ three times/week for another six weeks.

- Subgroup $B_{3}(n=6)$ were injected intra-peritoneal


week for another six weeks.

Blood samples collection: Before euthanization, blood samples were withdrawn to determine the white blood cells $\left(\mathrm{WBC}_{\mathrm{s}}\right)$, lymphocyte $\left(\mathrm{LYM}_{\mathrm{s}}\right)$, neutrophils $\left(\mathrm{NEU}_{\mathrm{s}}\right)$, and red blood cells count $\left(\mathrm{RBC}_{\mathrm{s}}\right)$ following the standard protocol used at Pharmacology Department, Faculty of Veterinary, Suez Canal University. The following steps were carried out. The animals were anesthetized by a cotton-soaked with diethyl ether. A fine heparinized capillary tube was introduced into the mesial angle 
of the eye. Blood samples were withdrawn into the heparinized capillary tubes and immediately sent to Hyah Hematology Laboratory, for counting, using fully automatic cell counter (Heco serc, Italy), with manual differential count.

Histopathological assessment: After animal's euthanization by a cotton-soaked with the lethal dose of diethyl ether, all pouches were fixed in $10 \%$ neutral formalin solution, processed, embedded in soft paraffin, left to be hardened and sectioned into $5 \mu \mathrm{m}$ using a rotary microtome, mounted on glass slides and stained with hematoxylin and eosin for light microscopic study. The slides were diagnosed by two pathologists and photographed by E-330 Olympus digital camera.

\section{Immunohistochemical assessment (IHC):}

From each paraffin block, $5 \mu \mathrm{m}$ sections were cut and mounted on positively charged slides. The anti-TNFa; rabbit polyclonal antibody was purchased from Gene Tex International Corporation, GTX110520. The steps of IHC were followed according to manufacturer's instructions. The positive interaction was expressed as brown cytoplasmic expression. Image analyzer computer system (image $\mathrm{J} /$ figi 1.46) was used to count the number of immune-positive cells as well as the number of the remaining unstained ones. The fraction of the positive cells was calculated.

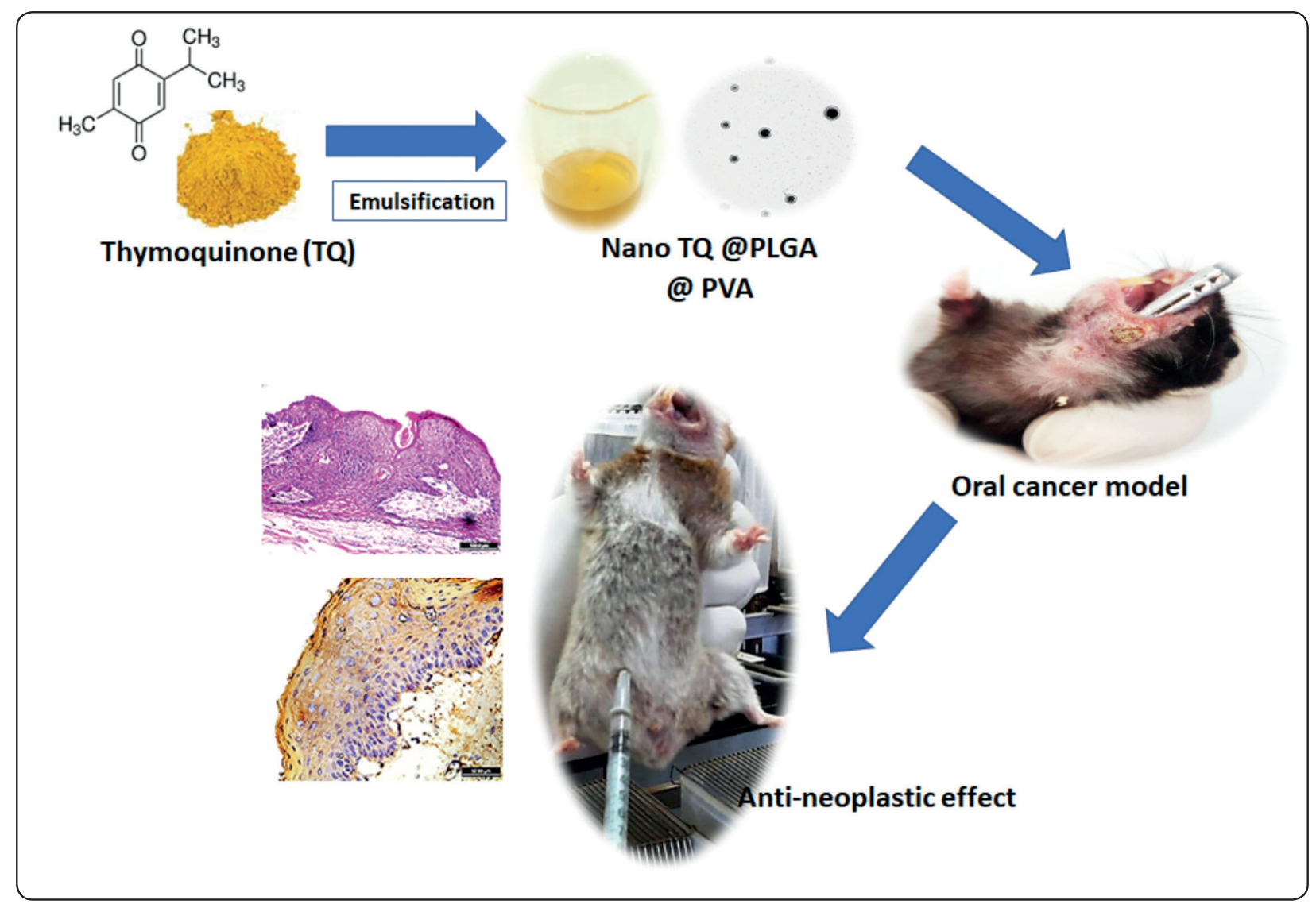

Graphical abstract represent the synthesis, characterization and hamster buccal pouch carcinogenesis effect 


\section{Statistical analysis:}

Microsoft excel 2013 was used for data entry and the statistical package for social science (SPSS) version 24 was used for data analysis. All values were expressed as mean \pm standard deviation. Comparisons between groups were performed using one-way analysis of variance (ANOVA). Probability value less than 0.005 was considered significant.

\section{RESULTS}

The high-resolution transmission electron microscope results

The TEM images obtained represented in Figure $1(a, b)$. As described form the images, the NPs appeared with a uniform well defined spherical shape and possessed a particle size around $200 \mathrm{~nm}$.

\section{Energy dispersive $\mathrm{x}$-ray microanalysis analysis}

The EDX chart for the fabricated solid biodegradable NPs in Figure 1 (c) detected two clear identified and strong lines corresponding to the carbon and oxygen elements. No other emission energies were observed as indication for the presence of pure NPs free from any contamination.

\section{Fourier transform infrared (ftir) spectroscopy results}

The IR charts for free TQ and TQ-PLGAPVA NPs were represented in Figure 1 (d). The FT-IR spectrum for the free TQ donated several characteristic peaks, among of them peak acquired at 2920 and $2966 \mathrm{~cm}^{-1}$ (C-H vibration bonds in methylene groups), $1635.35 \mathrm{~cm}^{-1}$ (carbonyl group $\mathrm{C}=\mathrm{O}$ stretch), $1462 \mathrm{~cm}^{-1}$ (C-H methyl rock), 1245 $\mathrm{cm}^{-1}, 1125 \mathrm{~cm}^{-1}, 1017 \mathrm{~cm}^{-1}$ (C-H in-plane bend) and $687 \mathrm{~cm}^{-1}$ ("oop" band C-H bend).

On the other hand, most of drug bands were changed and showed some broadening in their intensity after encapsulation to PLGA as appeared from the FT-IR chart of nano emulsion. However, the $\mathrm{C}-\mathrm{H}$ in-plane bending were shifted to $1253 \mathrm{~cm}^{-1}, 1192 \mathrm{~cm}^{-1}$ and Also the "oop" band
$\mathrm{C}-\mathrm{H}$ bend peak of free TQ in the IR spectrum of TQ-PLGA-PVA was appeared as very broad band centered at $583 \mathrm{~cm}^{-1}$. Furthermore, new peak appeared at $3413 \mathrm{~cm}^{-1}$ attributed to the characteristic $-\mathrm{OH}$ stretching band. As well as the peaks of $\mathrm{C}-\mathrm{O}$ stretching at $1050-1250 \mathrm{~cm}^{-1}$ and carbonyl $-\mathrm{C}=\mathrm{O}$ stretching at $1700-1800 \mathrm{~cm}^{-1}$ was clearly identified.

\section{Dynamic light scattering results}

The DLS measurement of the synthesized NPs in comparison with the pure TQ was introduced in Figure $1(\mathrm{e}, \mathrm{f})$. As indicated form the results, the polydispersity value for the TQ is 0.27 and the average particle size was $191 \mathrm{~nm}$ while Nano emulsion of TQ-PLGA-PVA NPs has PDI value 0.14 with average particle size $168 \mathrm{~nm}$. The PDI value is for NPs less than the original plant extract that means particles in more dispersity and to somewhat not agglomerated, this may be probably attributed to the presence of PVA as surfactant.

\section{Zeta-potential results}

The measurement of the synthesized NPs and pure TQ were shown in Figure $1(\mathrm{~g}, \mathrm{~h})$. The average zeta potential value for free TQ was $0.546 \mathrm{mV}$ while the TQ-PLGA-PVA NPs exhibited $-6.11 \mathrm{mV}$, suggesting a moderate stability of NPs.

\section{Blood samples results:}

The results revealed significant difference among these groups in WBC, LYM, NEU, and RBC count. Descriptive statistical analysis of means and standard deviations were summarized in table 1 . The mean difference was significant at $\mathrm{p}<0.05$. The statistically significant differences between groups were described in different letters. There was statistically significant increase in WBC and LYM total count in the subgroup $B_{1}$ (DMBA 12w) compared to all other groups. There was statistically significant increase in NEU, and RBCs total count in subgroup $\mathrm{B}_{3}$ (DMBA $6 \mathrm{w} / \mathrm{TQ}-\mathrm{PLGA} 6 \mathrm{w}$ ) near to negative control group compared to $\mathrm{B}_{2}$ (DMBA $6 \mathrm{w}$ / TQ 6 w) subgroup. 
TABLE (1) Descriptive statistical analysis of means and standard deviations. The mean difference is significant at $\mathrm{p}<0.05( \pm$ Standard deviation $)$

\begin{tabular}{|l|c|c|c|c|c|}
\hline & WBC $\times \mathbf{1 0}^{\mathbf{9}}$ cell// & LYM $\times \mathbf{1 0}^{\mathbf{9}}$ cell// & $\mathbf{N E U} \times \mathbf{1 0}^{\mathbf{9}}$ cell// & $\mathbf{R B C} \times \mathbf{1 0}^{\mathbf{9}}$ cell// & P value \\
\hline Negative group $(\mathrm{A})$ & $5.6 \pm 0.6^{(\mathrm{b})}$ & $5.1 \pm 0.6^{(\mathrm{c})}$ & $4.5 \pm 0.8^{(\mathrm{a})}$ & $8.2 \pm 0.1^{(\mathrm{a})}$ & \\
\hline Positive group $\left(\mathrm{B}_{1}\right)$ & $13.1 \pm 1.1^{(\mathrm{a})}$ & $8.1 \pm 0.8^{(\mathrm{a})}$ & $2.5 \pm 4.8^{(\mathrm{c})}$ & $4.8 \pm 0.3^{(\mathrm{c})}$ \\
\hline DMBA+TQ $\left(\mathrm{B}_{2}\right)$ & $6.9 \pm 0.1^{(\mathrm{c})}$ & $5.2 \pm 0.7^{(\mathrm{b})}$ & $4.0 \pm 2.1^{(\mathrm{a})}$ & $6.4 \pm 0.5^{(\mathrm{b})}$ & $<0.05$ \\
\hline DMBA+TQ-PLGA $\left(\mathrm{B}_{3}\right)$ & $5.4 \pm 0.6^{(\mathrm{b})}$ & $4.5 \pm 0.6^{(\mathrm{c})}$ & $5.3 \pm 2.5^{(\mathrm{a})}$ & $1.1 \pm 0.1^{(\mathrm{a})}$ & \\
\hline
\end{tabular}

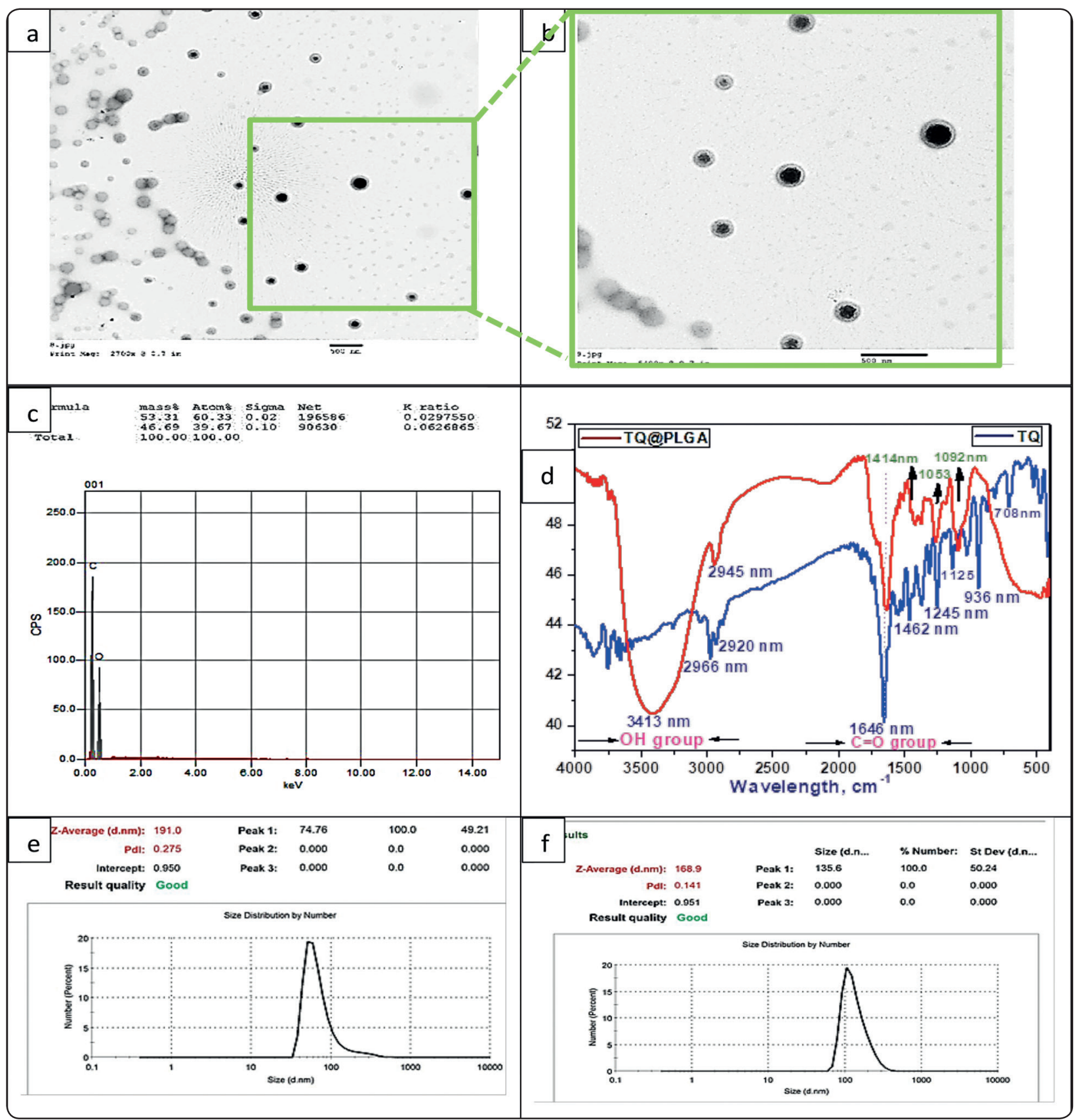




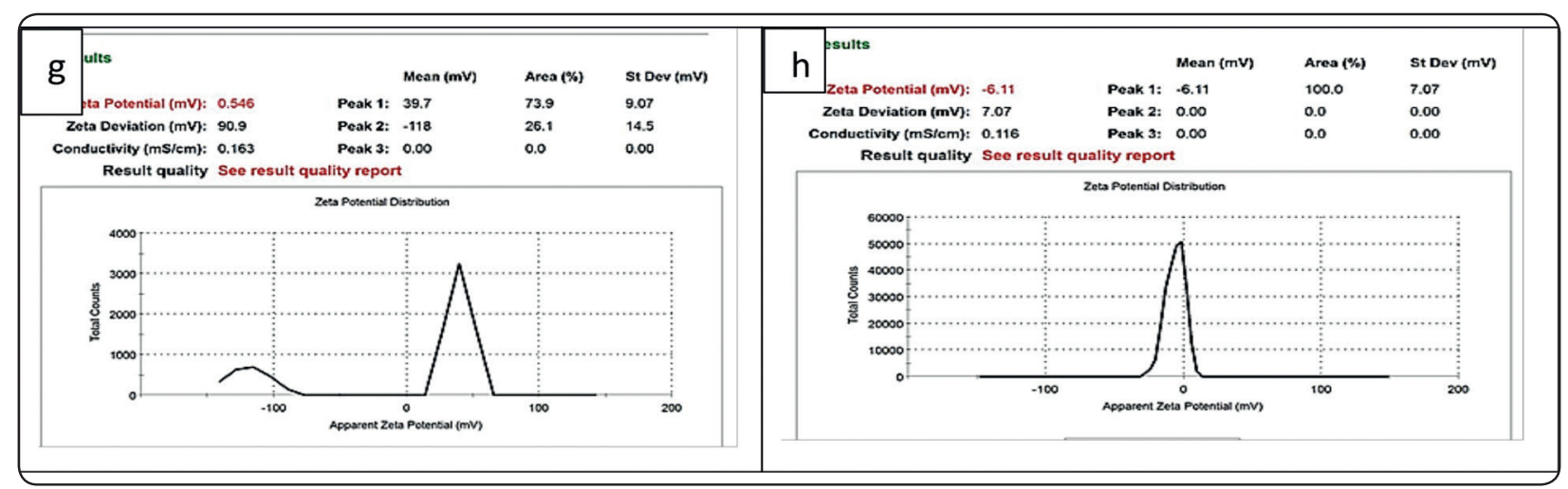

Fig. (1) (a, b) TEM images with different magnification scale for synthesized TQ-PLGA-PVA NPs. (c) The EDS spectra of TQPLGA-PVA NPs. (d) The FT-IR spectra for the free TQ and the synthesized TQ-PLGA-PVANP. (e,f) The DLS measurement for the pure TQ and TQ-PLGA-PVA NPs. $(\mathbf{g}, \mathbf{h})$ the zeta potential results for pure TQ and TQ-PLGA-PVA NPs

Histopathological and Immunohistochemical results: Figure 2, Table 2

Left pouches of the negative control group showed normal-appearing hamster buccal pouch's (HBP) mucous membrane. Thin stratified squamous epithelium formed of two to four cell layers lacking rete ridges, and thin keratin surface layer. The underlying connective tissue (c.t.) shows non inflamed loose connective tissue, with thin vascular spaces immediately below surface epithelium. Deeper c.t. layers formed of larger vessels and longitudinal striated muscle layer. Immunohistochemical results revealed mild cytoplasmic expression of TNF.

Left pouches of the animal group painted with DMBA for $6 \mathrm{w}$ then left untreated till $12 \mathrm{w}$ (positive control) revealed well differentiated squamous cell carcinomas in the form of large papillomatous lesions with invaded islands of epithelium into underlying connective tissue. Severe dysplastic epithelial changes were observed in the form of drop-shaped rete ridges, basilar hyperplasia, altered nuclear/cytoplasmic ratio, prominent nucleoli, hyperchromatism with cellular and nuclear pleomorphism. Immunohistochemical results revealed highly significant increase in cytoplasmic expression of TNF extending all over epithelial thickness.

The animal group painted with DMBA for $6 \mathrm{w}$ then injected intra-peritoneal with TQ for $6 \mathrm{w}$ revealed carcinoma in situ (CIS). The epithelium typically showed severe cellular and architectural changes, basilar hyperplasia, hyperchromatism and streaming of prickle cell layer.Immunohistochemical results revealed significant moderate increase in cytoplasmic expression of TNF.

The animal group painted with DMBA for $6 \mathrm{w}$ then injected intra-peritoneal with TQ-PLGA/ PVA for $6 \mathrm{w}$ revealed mild to moderate dysplastic criteria with hyperplasia and hyperkeratinization. Immunohistochemical results revealed significant decrease in cytoplasmic expression of TNF. 




Fig. (2): Photomicrographs showing (A) normal epithelial lining of hamster buccal pouch in group A (H\&E $\times 40)$, (B) low TNF immuno-reactivity $(\mathrm{IHC} \times 40),(\mathbf{C})$ DMBA-treated animals $\left(\mathrm{B}_{1}\right)$ showing invasive well differentiated SCC $(\mathrm{H} \& \mathrm{E} \times 20)$ (D) high power of Figure $\mathbf{C}$ showing multiple signs of dysplasia. (E) Intense TNF immuno-reactivity $($ IHC $\times 40)$. (F) Group $\mathrm{B}_{2}$ (DMBA 6w/TQ 6w) showing carcinoma in situ $(\mathrm{H} \& \mathrm{E} \times 20)$. (G) Intense TNF immuno-reactivity $($ IHC $\times 40)$. (H) Group $B_{4}($ DMBA 6w/TQ-PLGA 6w) showing moderate dysplasia $(H \& E \times 20)$. (I) low immuno-reactivity $($ IHC $\times 40)$.

TABLE (2): One-way ANOVA test showing the mean \pm standard deviations of TNF expression between negative group, DMBA group, TQ, and TQ-PLGA.

\begin{tabular}{|c|c|c|c|}
\hline Groups & N & Mean \pm standard deviation & P-value \\
\hline Negative group $(\mathrm{A})$ & 6 & $97.19 \pm 9.69^{\mathrm{d}}$ & \\
\hline Positive group $\left(\mathrm{B}_{1}\right)$ & 6 & $208.02 \pm 13.43^{\mathrm{a}}$ & $(\leq 0.05)$ \\
\hline DMBA+TQ $\left(\mathrm{B}_{2}\right)$ & 6 & $150.99 \pm 11.11^{\mathrm{b}}$ & \\
\hline DMBA+TQ-PLGA $\left(\mathrm{B}_{3}\right)$ & 6 & $100.11 \pm 4.45^{\mathrm{c}}$ & \\
\hline
\end{tabular}




\section{DISCUSSION}

During the last few decades, nanotechnology has established many essential applications for cancer treatment. Despite the excellent anticancer activity of phytochemicals, they have limited applications in the clinic due to low aqueous solubility, poor bioavailability, and poor cell penetration. This study aimed to overcome these draw backs through loading of thymoquinone on PLGA-PVA nano-formulation in treatment of OSCC induced in hamster buccal pouch. The best result was associated with TQPLGA in comparison with TQ alone. The possible explanation of the different outcomes could be attributed to the fact that nanoparticles can passively target tumor cells through the accumulation and trapping process known as enhanced permeability and retention (EPR) impact. An effect mediated through angiogenic vessels, and extravasation through leaky blood vessels (gaps 600nm), and improper lymphatic flow, seen mostly in solid tumors.

The physicochemical properties such as shape, size, morphology and charge are considered as the critical factors that may influenced the functional performance of any NPs based delivery design. The morphology specifications of the NPs play a significant role in assessment their adhesion, interaction and absorption with the body cells. The TEM results were consistent with the particle sizes measured by the particle analyzer. Furthermore, previous work which introduced the PLGA/PVA encapsulated Rhodamine B presented the TEM for prepared NPs with sizes $200 \mathrm{~nm}$ which was matched with present results. Additionally, another report attributed that the difference in the size and morphology due to the high molecular weight of polymers used PLGA and PVA. ${ }^{11}$

For demonstration, the nature of the molecular interactions within the PLGA and TQ solid, FT-IR spectroscopy was used. The FT-IR spectrum for the free TQ was matched with those obtained recently.
The shift in the C-H in-plane band and "oop" C-H band indicating occurred in the encapsulated form rather than free TQ, suggested the involving of these groups in the TQ during the encapsulation process into PLGA and hence ensured the interaction of the TQ to the PLGA carrier.

From PDI values, the addition surfactant fulfilled an important role through the emulsification process and accordingly protected the formed particles from coalescence. However, recent studies utilizing similar synthesis emulsification method using an emulsifier and polymer composition for hydrophobic compounds entrapment, obtained their polydispersity values oscillating from 0.2 to 0.3 which meant that their NPs were likely to aggregate. Previously Nallamuthu et al ${ }^{11}$ had prepared TQPLGA-PVA NPs, but he obtained the PDI value of 0.2 which meant that our prepared NPs by the modification done through preparation led to a significant increase in the particle stability.

The colloidal stability of fabricated NPs was demonstrated by the zeta-potential measurements. In general, it was reported that zeta potential values more than $+30 \mathrm{mV}$ or less than $-30 \mathrm{mV}$ were considered as a standard value to provide enough repulsion force to avoid particle aggregation. ${ }^{11}$ Our results matched with the previously detected by Mura et $\mathrm{al}^{25}$ who reported the influence of zeta potential when coating PLGA surface with different stabilizer polymers; whereas zeta potential value for PLA/PVA -5Mv.

In the present study, there were statistically significant increase in WBC and LYM counts in DMBA-painted group in comparison with phytochemical-treated groups. This finding indicated that the systemic toxic effect of DMBA resulting in non-reduction of WBC counts. DMBA is a potent immunosuppressive agent by lowering significantly, neutrophils as well as red blood cells (RBCs) which is a common complication with inflammatory diseases including cancer. While 
of interest, neutrophils and RBCs counts were improved in group $\mathrm{B}_{3}$ (TQ-PLGA) in a statistically significant level, which indicate the more immuneenhancing effect. Comparable finding were reported in many studies. Other study confirmed that the elevation of WBC count is highly associated with cancer mortality. During tumor development, mononuclear inflammatory cells (MICs) are often present at the early stages in close association with areas of hyperplasia and cellular atypia. These findings supported the concept that MICs are the driving force for tumor initiation and/or progression. Also, mast cells and neutrophils can also support tumor development by leading to up-regulation of pro-inflammatory cytokines, such as interferon- $\gamma$, tumor necrosis factor (TNF), and interleukin (IL)-1, which were observed in patients with oral cancer.

The histopathological changes followed DMBA painting showed well differentiated SCC seen in the $12^{\text {th }}$ week of the study. This finding was in line with other studies.' Manoharan et al had supported that DMBA might have induced oral carcinogenesis through chronic inflammation in the hamster buccal pouch. The promising result was attributed to TQPLGA group, which showed histopathological improvement in the form of moderate dysplasia while TQ-treated group showed carcinoma in situ. This improvement insures proper anti-neoplastic effect of TQ especially when loaded on PLGA. Several studies in agreement with these results using various phytochemicals in nano-formulations. ${ }^{11}$,

As for evaluating the immunohistochemical results, there was highly significant increase in TNF cytoplasmic expression in DMBA-painted and TQtreated groups. This finding confirmed that cytokines such as tumor necrosis factor- $\alpha$ (TNF- $\alpha$ ) exert biological effects on tumor development which produced by variety of cells including macrophages, fibroblasts and endothelial cells, as well as neoplastic cells. TNF- $\alpha$ binds to cell surface receptors (TNF- $\alpha$ ) to initiate multiple signal transduction pathways, in- cluding mitogen activated protein (MAP) kinases, and the driving gene nuclear factor kappa B (NF$\varkappa \mathrm{B})$ pathways. Recent study suggested that TNF- $\alpha$ enhanced the invasion and metastasis ability of OSCC cells via the NF- $x \mathrm{~B}$ signaling pathway. Of great interest, the significant decrease in TNF cytoplasmic expression which noticed with TQ-PLGA group. This finding was in line with the theory that, TQ has immune-modulatory activity. Other study reported that oral administration of TQ significantly reduced the serum levels of IL-1 $\beta$ and TNF- $\alpha$ as well as a number of inflammatory mediators. Krishnan et al correlated the concentration of the TNF- $\alpha$ levels with histological differentiation of OSCC in comparison with premalignant oral lesions. Deepthi $\mathrm{G}$ et al supported the utility of salivary TNF- $\alpha$ as an indicator for the neoplastic transformation from oral potentially malignant lesions to oral squamous cell carcinoma.

\section{CONCLUSIONS}

Nano-encapsulation for TQ was successfully performed and effectively characterized. The nanoemulsion overcame the poor bioavailability for thymoquinone. Systemic application of TQ-PLGA was considered a promising chemo-therapeutic agent in tumors regression and TNF $-\alpha$ could be used as a prognostic biomarker of OSCC.

\section{REFERENCES}

1. Ghantous Y, Abu Elnaaj I. Global incidence and risk factors of oral cancer. Harefuah. 2017 ;156(10):645-649.

2. George A, Sreenivasan BS, Sunil S, Soma SV, Jubin Thomas, Devi Gopakumar, Mani V. Potentially malignant disorders of oral cavity. Oral \& Maxillofac Pathol J. 2011; 2: $95-100$.

3. Omura $\mathrm{K}$ :Current status of oral cancer treatment strategies: surgical treatments for oral squamous cell carcinoma.Int $\mathbf{J}$ Clin Oncol.2014; 19(3): 423-430.

4. Hemalswarya S and Doble M. Potential synergism of natural products in the treatment of cancer. Phytother Res.2006; 20(4): 239-249. 
5. Badary OA, Abd-Ellah MF, El-Mahdy MA, Salama SA, Hamada FM. Anticlastogenic activity of thymoquinone against benzo(a)pyrene in mice. Food Chem Toxicol 2007;45:88-92.

6. Gali-Muhtasib H, Diab-Assaf M, Boltze C, Al-Hmaira J, Hartig R, Roessner A. Thymoquinone extracted from black seed triggers apoptotic cell death in human colorectal cancer cells via a p53- dependent mechanism. Inte $\mathrm{J}$ of oncol 2004;25:857-866.

7. Kus G, Ozkurt M, Kabadere S, Erkasap N, Goger G, Demirci F. Antiproliferative and antiapoptotic effect of thymoquinone on cancer cells in vitro. Bratisl Lek Listy; 2018; 119 (5):312-316.

8. Siddiqui IA, Adhami VM, Ahmad N, Mukhtar H. Nanochemoprevention: Sustained release of bioactive food components for cancer prevention. Nut Cancer. 2010; 62(7): 883-890.

9. Alexis F, Pridgen E, Molnar LK, Farokhzad OC. Factors affecting the clearance and biodistribution of polymeric nanoparticles. Mol Pharm. 2008; 5:505-515.

10. Masood F. Polymeric nanoparticles for targeted drug delivery system for cancer therapy. Mater Sci Eng C Mater Biol Appl. 2016;60: 569-578.

11. Nallamuthu I, Parthasarathi A, Khanum F. Thymoquinoneloaded PLGA nanoparticles: Antioxidant and antimicrobial properties. Int. Curr. Pharm. J. 2013, 2, 202-207.

12. Ahmad R, Kaus NHM, Hamid S. Synthesis and characterization of PLGA-PEG thymoquinone nanoparticles and its cytotoxicity effects in tamoxifen-resistant breast cancer cells. Adv Exp Med Biol. 2018: 1-18. Dec 18. doi: 10.1007/5584_2018_302.

13. Bendaly J, Zhao S, Neale JR, Metry KJ, Doll MA, States JC, Pierce WM, Hein DW. 2-Amino-3,8-dimethylimidazo[4,5-f]quinoxaline-induced DNA adduct formation and mutagenesis in DNA repair-deficient Chinese hamster ovary cells expressing human cytochrome P450 1A1 and rapid or slow acetylator $\mathrm{N}$-acetyltransferase 2. Cancer Epidemiol Biomar Prev. 2007;16(7):1503-1509.

14. Salley JJ. Experimental carcinogenesis in the cheek pouch of the Syrian hamster. Dent Res J. 1954;33(2):253-262.

15. Wang D. Dubois, R.N. Eicosanoids and cancer. Nat. Rev. Cancer 2010, 10, 181-193.

16. Li Y, Dejin Z, Ren-He X. Critical role of tumor necrosis factor signaling in mesenchymal stem cell-based therapy for autoimmune and inflammatory diseases. front in immunol. 2018; 9:01658.
17. Devin A, Cook A, Lin Y, Rodriguez Y, Kelliher M, Liu Z. The distinct roles of TRAF2 and RIP in IKK activation by TNF-R1: TRAF2 recruits IKK to TNF-R1 while RIP mediates IKK activation. Immunity 2000;12:419-429.

18. Stuelten CH, DaCosta Byfield S, Arany PR, Karpova TS, Stetler-Stevenson WG, Roberts AB. Breast cancer cells induce stromal fibroblasts to express MMP-9 via secretion of TNF-alpha and TGF-beta. J Cell Sci. 2005; 118:21432153.

19. Xie X, Tao Q, Zou Y, Zhang F, Guo M, Wang Y, Wang H, Zhou Q, Yu S. PLGA nanoparticles improve the oral bioavailability of curcumin in rats: characterizations and mechanisms. Journal of agricultural and food chemistry, 2011. 59(17): p. 9280-9289.

20. Faul F, Erdfelder E, Lang AG, and Buchner A.. G*Power 3: A flexible statistical power analysis program for the social, behavioral, and biomedical sciences. Behavior Research Methods. 2007;39: 175-191.

21. Khafaji M, Zamani M, Golizadeh M, Bavi O. Inorganic nanomaterials for chemo/photothermal therapy: a promising horizon on effective cancer treatment. Biophys Rev. 2019;11(3): 335-352.

22. Martínez-Ballesta M, Gil-Izquierdo Á, García-Viguera C, Domínguez-Perles R. Nanoparticles and Controlled Delivery for Bioactive Compounds: Outlining Challenges for New "Smart-Foods" for Health. Foods. 2018;7(5) 72.

23. Patra CR, Bhattacharya R, Mukhopadhyay D, Mukherjee P. Fabrication of gold nanoparticles for targeted therapy in pancreatic cancer. Adv Drug Deliv Rev. 2010;62:346-361.

24. Ahsan F, Rivas IP, Khan MA, Torres Suarez AI. Targeting to macrophages: role of physicochemical properties of particulate carriers liposomes and microspheres on the phagocytosis by macrophages. J control release, 2002. 79(1-3): 29-40.

25. Mura S, Hillaireau H, Nicolas J, Le Droumaguet B, Gueutin C, Zanna S, Tsapis N, Fattal E. Influence of surface charge on the potential toxicity of PLGA nanoparticles towards Calu-3 cells. International journal of nanomedicine, 2011. 6: p. 2591- 2605.

26. Surekha R and Sumathi T. An efficient encapsulation of thymoquinone using solid lipid nanoparticle for brain targeted drug delivery: physicochemical characterization, pharmacokinetics and bio-distribution studies. Int $\mathrm{J}$ Pharmaceut Clinic Res. 2016; 8(12):1616-1624.

27. Pereira MC, Hill LE, Zambiazi RC, Talcott SM, Talcott S, Gomesb CL. Nanoencapsulation of hydrophobic phy- 
tochemicals using poly (DL-lactide-co-glycolide)(PLGA) for antioxidant and antimicrobial delivery applications: Guabiroba fruit (Campomanesia xanthocarpa O. Berg) study. LWT-Food Science and Technology, 2015. 63(1): 100-107.

28. Gomes C, Moreira RG, Castell-Perez E. Poly (DL-lactideco-glycolide)(PLGA) nanoparticles with entrapped transcinnamaldehyde and eugenol for antimicrobial delivery applications. Journal of Food Science, 2011. 76(2): 16-24.

29. El-Sherbiny RH, Hassan MM, Korraah AM. Effect of different nanothymoquinone concentrations on the chemically-induced epithelial dysplasia in the hamster buccal pouch. Suez Canal Uni Med J. 2017;10(20): 75-88.

30. Jagatheesh K, Arumugam V, Elangovan N, PavanKumar P. Evaluation of the anti-tumor and antioxidant activity of morphophallus Paeonifolius on DMBA induced mammary carcinoma. Int J Chem Pharma Sci. 2010;1: 40-50.

31. Iida M, Ikeda F, Ninomiya T, Yonemoto K, Doi Y, Hata J, Matsumoto T, Iida M, Kiyohara Y. White blood cell count and risk of gastric cancer incidence in a general Japanese population. Am J Epidemiol.2012;10: 1-7.

32. Mantovani A, Schioppa T, Porta C, Allavena P, Sica A. Role of tumor- associated macrophages in tumor progression and invasion. Cancer Metastasis Rev. 2006; 25: 315 322.

33. Bano S, David MP, Indira AP. Salivary biomarkers for oral squamous cell carcinoma: an overview. IJSS Case Rep Rev. 2015;1(8): 39-45.

34. Hassan MA, El-Dakhakhny M. Effect of some Nigella sativa constituents on chemical carcinogenesis in hamster cheek pouch. Egypt Soci Pharmacol Exper Ther J. 1992;11: 675-687.

35. El-Dakhakhny M, Hassan MA, Abd El-Aziz G. Effect of thymoquinone and polythymoqunione on chemicallyinduced oral epithelial dysplasia (experimental study). Int Acad Res J. 2009; 1(2): 107-117.

36. Manoharan S, Sindhu G, Nirmal MR, Vetrichelvi V, Balakrishnan S. Protective effect of berberine on expression pattern of apoptotic, cell proliferative, inflammatory and angiogenic markers during 7,12dimethylbenz(a)anthra- cene-induced hamster buccal pouch carcinogenesis. Pak J Biol Sci. 2011;14(20):918-932.

37. El-Hossary W, Hegazy E, Elmansy M. Topical chemopreventive effect of thymoquinone versus thymoquinone loaded on gold nanoparticles on DMBA-induced hamster buccal pouch carcinogenesis (immunohistochemical study). Egy Dent J. 2018; 64: 733-746.

38. May LT, Ghrayeb J, Santhanam U, Tatter SB, Sthoeger Z, Helfgott DC. Synthesis and secretion of multiple forms of $\beta 2$-interferon/B-cell differentiation factor $2 /$ hepatocytestimulating factor by human fibroblasts and monocytes. J Biol Chem, 263, 7760-7766 (1998).

39. Ardestani S, Li B, Deskins DL, Wu H, Massion PP, Young PP. Membrane versus soluble isoforms of TNF- $\alpha$ exert opposing effects on tumor growth and survival of tumorassociated myeloid cells. Cancer Res. 2013;73(13):39383950 .

40. Tang D, Tao D, Fang Y, Deng C, Xu Q, Zhou J. TNF-alpha promotes invasion and metastasis via NF-kappa B pathway in oral squamous cell carcinoma. Medical science monitor basic research. 2017; 23:141-149.

41. Badr G, Alwasel S, Ebaid H, Mohany M, Alhazza I. Perinatal supplementation with thymoquinone improves diabetic complications and $\mathrm{T}$ cell immune responses in rat offspring. Cell Immunol. 2011; 267:133-140.

42. Umar S, Zargan J, Umar K, Ahmad S, Katiyar CK, Khan HA. Modulation of the oxidative stress and inflammatory cytokine response by thymoquinone in the collagen induced arthritis in Wistar rats. Chem Biol Interact. 2012; 197:40-46.

43. Krishnan R, Thayalan DK, Padmanaban R, Ramadas R, Annasamy RK, Anandan N. Association of serum and salivary tumor necrosis factor- $\alpha$ with histological grading in oral cancer and its role in differentiating premalignant and malignant oral disease. Asian Pac J Cancer Prev. 2014;15: 7141-7148

44. Deepthi G, Nandan SR, Kulkarni PG. Salivary Tumour necrosis factor- $\alpha$ as a biomarker in oral leukoplakia and oral squamous cell carcinoma. Asian Pac J Cancer Prev. 2019;20(7):2087-2093. 